\title{
Adding TiC Nanoparticles to Magnesium Alloy ZK60A for Strength/Ductility Enhancement
}

\author{
Muralidharan Paramsothy, ${ }^{1}$ Jimmy Chan, ${ }^{2}$ Richard Kwok, ${ }^{2}$ and Manoj Gupta ${ }^{1}$ \\ ${ }^{1}$ Department of Mechanical Engineering, National University of Singapore, 9 Engineering Drive 1, Singapore 117576 \\ ${ }^{2}$ Singapore Technologies Kinetics Ltd. (ST Kinetics), 249 Jalan Boon Lay, Singapore 619523 \\ Correspondence should be addressed to Manoj Gupta, mpegm@nus.edu.sg
}

Received 10 March 2011; Accepted 29 June 2011

Academic Editor: Theodorian Borca-Tasciuc

Copyright ( 2011 Muralidharan Paramsothy et al. This is an open access article distributed under the Creative Commons Attribution License, which permits unrestricted use, distribution, and reproduction in any medium, provided the original work is properly cited.

\begin{abstract}
ZK60A nanocomposite containing TiC nanoparticles was fabricated using solidification processing followed by hot extrusion. The ZK60A nanocomposite exhibited similar grain size to monolithic ZK60A and significantly reduced presence of intermetallic phase, reasonable TiC nanoparticle distribution, nondominant $\left(\begin{array}{llll}0 & 0 & 0 & 2\end{array}\right)$ texture in the longitudinal direction, and $16 \%$ lower hardness than monolithic ZK60A. Compared to monolithic ZK60A (in tension), the ZK60A nanocomposite simultaneously exhibited higher $0.2 \%$ TYS, UTS, failure strain, and work of fracture (WOF) $(+13 \%,+15 \%,+76 \%$, and $+106 \%$, resp.). Also, compared to monolithic ZK60A (in compression), the ZK60A nanocomposite exhibited lower $0.2 \%$ CYS (-17\%) and higher UCS, failure strain, and WOF $(+11 \%$, $+29 \%$, and $+34 \%$, resp.). The beneficial effect of adding TiC nanoparticles on the enhanced tensile and compressive response of $\mathrm{ZK} 60 \mathrm{~A}$ is investigated in this paper.
\end{abstract}

\section{Introduction}

Magnesium alloys based on the Mg-Zn combination (such as ZK60A from the Mg-Zn-Zr system) are well known for their precipitation hardening characteristics during ageing [1]. Here, MgZn' (or metastable $\beta_{1}$ ' phase) forms as rods parallel to the c-axis of the HCP unit cell, while metastable $\beta_{2}$ ' phase forms as discs parallel to the (llllll 000 basal plane of the HCP unit cell [2-6]. The $\beta_{1}$ ' phase has been reported to have a monoclinic structure similar to that of $\mathrm{Mg}_{4} \mathrm{Zn}_{7}$ in aged $\mathrm{Mg}$ 8 wt.\% Zn alloy [2]. The yield strength of quasicrystalline particle reinforced $\mathrm{Mg}-\mathrm{Zn}-\mathrm{Y}$ and $\mathrm{Mg}-\mathrm{Zn}-\mathrm{Y}-\mathrm{Zr}$ magnesium alloys was observed to increase with the volume fraction of the quasicrystalline phase [7]. This was based on the strengthening effect of the quasicrystalline particles [7]. Due to low particle-matrix interfacial energy, icosahedral particles in the Mg-Zn-Y alloy have been observed to be stable against coarsening during elevated temperature deformation [7]. ZK60A is commonly used in structural applications based on the following characteristics: (a) high strength and ductility after T5 aging, (b) good creep resistance, (c) poor arc weldability due to hot-shortness cracking, and (d) excellent resistance weldability. $\mathrm{Al}_{2} \mathrm{O}_{3}$ nanoparticles were added to
ZK60A recently using disintegrated melt deposition (DMD) $[8,9]$ followed by hot extrusion and heat treatment. In the study, the $\mathrm{Al}_{2} \mathrm{O}_{3}$ nanoparticles were agglomerated and not well dispersed in the ZK60A matrix [10]. This resulted in (1) tensile/compressive strength of ZK60A increasing (without significant loss in ductility) in the presence of 1.0 vol.\% $\mathrm{Al}_{2} \mathrm{O}_{3}$ nanoparticles and (2) tensile/compressive ductility increasing (without significant loss in strength) in the presence of $1.5 \mathrm{vol} . \% \mathrm{Al}_{2} \mathrm{O}_{3}$ nanoparticles [10]. It was also observed that $\mathrm{Zr}$ and $\mathrm{Zn}$ were leached out of the $\mathrm{ZK} 60 \mathrm{~A}$ matrix by the agglomerates of $\mathrm{Al}_{2} \mathrm{O}_{3}$ nanoparticles [10]. Carbon nanotubes (CNTs) were also added to ZK60A recently using DMD $[8,9]$ followed by hot extrusion. Here, CNTs were not agglomerated but reasonably well distributed in the ZK60A matrix [11]. This enabled (1) simultaneous increase in tensile strength and ductility of ZK60A and (2) significant increase in compressive ductility (with significant decrease in compressive strength) of ZK60A [11]. Also, the intermetallic phase(s) precipitation was reported to be possibly regulated at nanoscale in this nanocomposite [11]. Dissolved $\mathrm{Zn}$ segregation at the liquid-SiC nanoparticle interface in a cast $\mathrm{ZK} 60 \mathrm{~A} / \mathrm{SiC}$ nanocomposite which enabled nanoscale $\mathrm{MgZn}_{2}$ precipitation has also been discussed in detail [12]. 
$\mathrm{Ti}$ and $\mathrm{C}$ are not known to react actively with molten Mg. This is favourable concerning metal-matrix composite processing for structural applications where particlematrix interfacial reactions leading to inferior mechanical properties are undesirable. Regarding TiC reinforced metalmatrix composites, molten $\mathrm{Al}-\mathrm{Mg}$ alloys were infiltrated at $900^{\circ} \mathrm{C}$ into TiC preforms with flowing argon [13]. Wetting of TiC substrates by the molten $\mathrm{Al}-\mathrm{Mg}$ alloys was investigated in this work [13]. It was observed that (1) selective $\mathrm{Al}_{4} \mathrm{C}_{3}$ formation was present at the matrix-preform interface and (2) $\mathrm{TiAl}_{3}$ traces were present in the Al-based matrix [13]. Also, a preform containing elemental powders of $\mathrm{Ti}$ and $\mathrm{C}$ (where $\mathrm{TiC}$ was formed in situ) was initially formed [14]. Molten magnesium alloy AZ91D was pressurelessly infiltrated into this Ti-C preform and tensile properties of the composite were compared to monolithic AZ91D [14]. Here, the in situ formed TiC reinforcement enhanced the tensile strength especially at higher temperatures [14]. The strain hardening exponent $(n)$ of the AZ91D/TiC composite was higher at 0.71-0.82 compared to that of monolithic AZ91D being 0.11-0.32 (for tensile deformation carried out at $423-723 \mathrm{~K}$ in each case) [14]. The mechanical properties of hot pressed $\mathrm{W}$ were improved based on the addition of $\mathrm{La}_{2} \mathrm{O}_{3}$ and $\mathrm{TiC}$ [15]. Here, the $\mathrm{W}$ matrix was strengthened due to the reinforcement particles pinning down the grain boundaries and inhibiting grain growth during sintering [15]. TiC particles exhibited good interfacial characteristics (for effective load transfer) with the adjacent $\mathrm{W}$ matrix while $\mathrm{La}_{2} \mathrm{O}_{3}$ particles were beneficial for sintering and densification of composites [15]. The collective strengthening effect of $\mathrm{La}_{2} \mathrm{O}_{3}$ and $\mathrm{TiC}$ particles on $\mathrm{W}$ was better than that of either $\mathrm{La}_{2} \mathrm{O}_{3}$ or $\mathrm{TiC}$ [15]. It was recently reported that $\mathrm{TiC}$ formed in situ when CNT was added to pure Ti powder and the mixture was consolidated using spark plasma sintering followed by hot extrusion [16]. Here, the titanium matrix nanocomposite exhibited significantly higher yield and ultimate strengths without considerably compromising ductility compared to monolithic $\mathrm{Ti}$ [16]. Open literature search has revealed that no successful attempt has been made to simultaneously increase tensile strength and ductility of ZK60A magnesium alloy with TiC or any other Ti-based nanoparticles, using a high volume production spray-deposition-based solidification processing technique.

Accordingly, one of the primary aims of this study was to simultaneously increase tensile strength and ductility of ZK60A magnesium alloy with TiC nanoparticles. Another aim of the present study was to evaluate the compressive properties of ZK60A/TiC magnesium alloy nanocomposite. Disintegrated melt deposition (DMD) $[8,9]$ followed by hot extrusion was used to synthesize the $\mathrm{ZK} 60 \mathrm{~A} / \mathrm{TiC}$ magnesium alloy nanocomposite.

\section{Experimental Procedures}

2.1. Materials. In this study, ZK60A (nominally 4.80$6.20 \mathrm{wt} . \% \mathrm{Zn}, 0.45 \mathrm{wt} . \% \mathrm{Zr}$, balance $\mathrm{Mg}$ ) supplied by Tokyo Magnesium Co. Ltd. (Yokohama, Japan) was used as the matrix material. ZK60A block was sectioned to smaller pieces. All oxide and scale surfaces were removed using machining. All surfaces were washed with ethanol after machining. TiC nanoparticles $(98+\%$ purity, 30$50 \mathrm{~nm}$ size) supplied by Nanostructured and Amorphous Materials Inc. (Tex, USA) was used as the reinforcement phase.

\subsection{Processing. Monolithic $\mathrm{ZK} 60 \mathrm{~A}$ was cast using the $\mathrm{DMD}$} method $[8,9]$. This involved heating ZK60A blocks to $750^{\circ} \mathrm{C}$ in an inert Ar gas atmosphere in a graphite crucible using a resistance heating furnace. The crucible was equipped with an arrangement for bottom pouring. Upon reaching the superheat temperature, the molten slurry was stirred for $2.5 \mathrm{~min}$ at $460 \mathrm{rpm}$ using a twin blade (pitch $45^{\circ}$ ) mild steel impeller to facilitate the uniform distribution of heat. The impeller was coated with Zirtex $25(86 \%$ $\mathrm{ZrO}_{2}, 8.8 \% \mathrm{Y}_{2} \mathrm{O}_{3}, 3.6 \% \mathrm{SiO}_{2}, 1.2 \% \mathrm{~K}_{2} \mathrm{O}$ and $\mathrm{Na}_{2} \mathrm{O}$, and $0.3 \%$ trace inorganics) to avoid iron contamination of the molten metal. The melt was then released through a $10 \mathrm{~mm}$ diameter orifice at the base of the crucible. The melt was disintegrated by two jets of argon gas oriented normal to the melt stream and located $265 \mathrm{~mm}$ from the melt pouring point. The argon gas flow rate was maintained at $25 \mathrm{dm}^{3} \mathrm{~min}^{-1}$. The disintegrated melt slurry was subsequently deposited onto a metallic substrate located $500 \mathrm{~mm}$ from the disintegration point. An ingot of $40 \mathrm{~mm}$ diameter was obtained following the deposition stage. To form the ZK60A/1.5 vol.\% TiC nanocomposite (see Figure 1), TiC nanoparticle powder was isolated by wrapping in $\mathrm{Al}$ foil of minimal weight $(<0.50 \mathrm{wt} . \%$ with respect to ZK60A matrix weight) and arranged on top of the ZK60A blocks, with all other DMD parameters unchanged. All deposited ingots were sectioned into billets. All billets were machined to $35 \mathrm{~mm}$ diameter and hot extruded using 20.25: 1 extrusion ratio on a 150 ton hydraulic press. The extrusion temperature was $350^{\circ} \mathrm{C}$. The billets were held at $400^{\circ} \mathrm{C}$ for $60 \mathrm{~min}$ in a furnace prior to extrusion. Colloidal graphite was used as a lubricant. Rods of $8 \mathrm{~mm}$ were obtained.

2.3. Microstructural Characterization. Microstructural characterization studies were conducted on metallographically polished monolithic and nanocomposite extruded samples to determine grain characteristics as well as nanoparticle reinforcement distribution. Hitachi S4300 Field-Emission SEM was used. Image analysis using Scion software was carried out to determine the grain characteristics. XRD studies were conducted using $\mathrm{CuK}_{\alpha}$ radiation $(\lambda=1.5406 \AA)$ with a scan speed of $2^{\circ} / \mathrm{min}$ in an automated Shimadzu LAB-X XRD-6000 diffractometer to determine intermetallic phase(s) presence and dominant textures in the transverse and longitudinal (extrusion) directions.

2.4. Hardness. Microhardness measurements were made on polished monolithic and nanocomposite extruded samples. Vickers microhardness was measured with an automatic digital Shimadzu HMV Microhardness Tester using 25 gfindenting load and $15 \mathrm{~s}$ dwell time. 


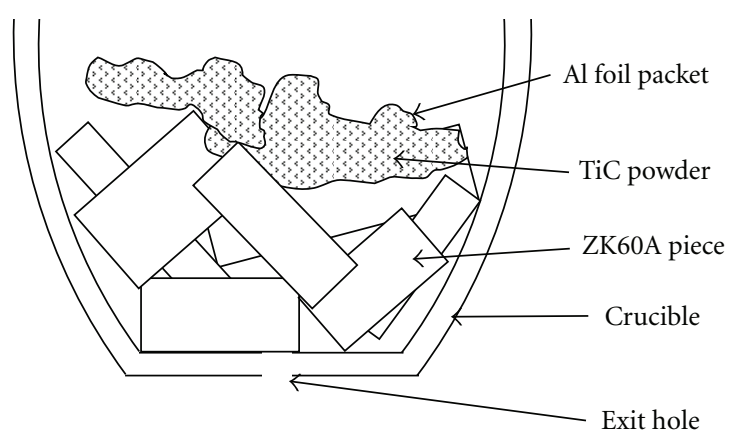

FIgURe 1: Arrangement of raw materials in crucible before casting for ZK60A/TiC nanocomposite.

2.5. Tensile Testing. Smooth bar tensile properties of the monolithic and nanocomposite extruded samples were determined based on ASTM E8M-05. Round tension test samples of $5 \mathrm{~mm}$ diameter and $25 \mathrm{~mm}$ gauge length were subjected to tension using an MTS 810 machine equipped with an axial extensometer with a crosshead speed set at $0.254 \mathrm{~mm} / \mathrm{min}$. Fractography was performed on the tensile fracture surfaces using Hitachi S4300 FESEM.

2.6. Compressive Testing. Compressive properties of the monolithic and nanocomposite extruded samples were determined based on ASTM E9-89a. Samples of $8 \mathrm{~mm}$ length $(l)$ and $8 \mathrm{~mm}$ diameter $(d)$ where $l / d=1$ were subjected to compression using an MTS 810 machine with $0.005 \mathrm{~min}^{-1}$ strain rate. Fractography was performed on the compressive fracture surfaces using Hitachi S4300 FESEM.

\section{Results}

3.1. Macrostructural Characteristics. No macropores or shrinkage cavities were observed in the cast monolithic and nanocomposite materials. No macrostructural defects were observed for extruded rods of monolithic and nanocomposite materials.

3.2. Microstructural Characteristics. Microstructural analysis results revealed that grain size was statistically unchanged in the case of nanocomposite as shown in Table 1 and Figure 2(a). Unlike monolithic ZK60A, intermetallic phase(s) were not detected in the nanocomposite by X-ray diffraction as shown in Figure 2(b). The distribution of individual TiC nanoparticles present in the nanocomposite (at the grain boundary and within the grain) was reasonably uniform as shown in Figures 2(c) and 2(d).

Texture results are listed in Table 2 and shown in Figure 3. In monolithic and nanocomposite materials, the dominant texture in the transverse and longitudinal directions was $\left(\begin{array}{llll}1 & 0 & -1 & 1\end{array}\right)$.

3.3. Hardness. The results of microhardness measurements are listed in Table 1. The nanocomposite exhibited lower hardness than the monolithic material.
3.4. Tensile Behavior. The overall results of ambient temperature tensile testing of the extruded materials are shown in Table 3 and Figure 4(a). The strength, failure strain, and work of fracture (WOF) of ZK60A/1.5 vol.\% TiC were significantly higher compared to monolithic ZK60A. The WOF was determined by computing the area under the stress-strain curve up to the point of fracture. The fractured surface of all extruded materials exhibited mixed (ductile + brittle) mode of fracture as shown in Figures 5(a) and 5(b).

3.5. Compressive Behavior. The overall results of ambient temperature compressive testing of the extruded materials are shown in Table 4 and Figure $4(\mathrm{~b})$. The $0.2 \%$ CYS of ZK60A/1.5 vol.\% TiC was lower compared to monolithic ZK60A. The UCS, failure strain, and work of fracture (WOF) of ZK60A/1.5 vol.\% TiC were significantly higher compared to monolithic ZK60A. The fractured surface of $\mathrm{ZK} 60 \mathrm{~A} / 1.5 \mathrm{vol} . \% \mathrm{TiC}$ appeared smoother than that of monolithic ZK60A as shown in Figures 5(c) and 5(d).

\section{Discussion}

4.1. Synthesis of Monolithic ZK60A and ZK60A/TiC Nanocomposite. Synthesis of monolithic and nanocomposite materials, the final form being extruded rods, was successfully accomplished with (a) no detectable metal oxidation and (b) no detectable reaction between graphite crucible and melts. The inert atmosphere used during DMD was effective in preventing oxidation of the Mg melt. No stable carbides formed due to reaction with the graphite crucible.

4.2. Microstructural Characteristics. Microstructural characterization of extruded samples is discussed in terms of (a) grain and intermetallic phase(s) characteristics and (b) $\mathrm{TiC}$ nanoparticle reinforcement distribution.

Nearly equiaxed grains were observed in monolithic material and nanocomposite as shown in Table 1 and Figure 2(a). Grain size was statistically unchanged in the case of nanocomposite, suggesting the inability of TiC nanoparticles to serve as either nucleation sites or obstacles to grain growth during solid state cooling. Intermetallic phase(s) were not observed within the resolution of XRD (less than $2 \%$ by volume) as well as FESEM in the nanocomposite. This indicated that the intermetallic particle size in the nanocomposite was significantly lower compared to that of monolithic ZK60A. It is well known that crystalline nanoparticles can have insufficient Bragg diffraction planes needed for exhibiting strong diffraction peaks in goniometer-based XRD [17]. This resulted in the corresponding absence of strong diffraction peaks pertaining to intermetallic phase(s) in the XRD scan. The intermetallic phase(s) precipitation was possibly regulated at nanoscale due to the presence of (a) dissolved $\mathrm{Al}$ and/or (b) well-dispersed $\mathrm{TiC}$ nanoparticles. In the case of (a), dissolved $\mathrm{Al}$ possibly altered the intermetallic phase stabilities in the ZK60A matrix. This is similar to free $\mathrm{Si}$ from $\mathrm{SiC}$ nanoparticles being possibly responsible for altered intermetallic phase stabilities in $\mathrm{Mg}-\mathrm{Zn}$ alloys as recently reported [12]. In the case of (b), dissolved $\mathrm{Zn}$ 


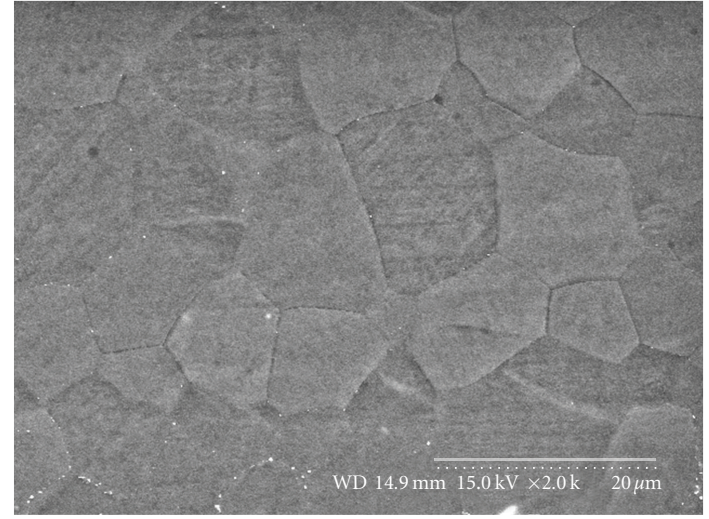

(a)

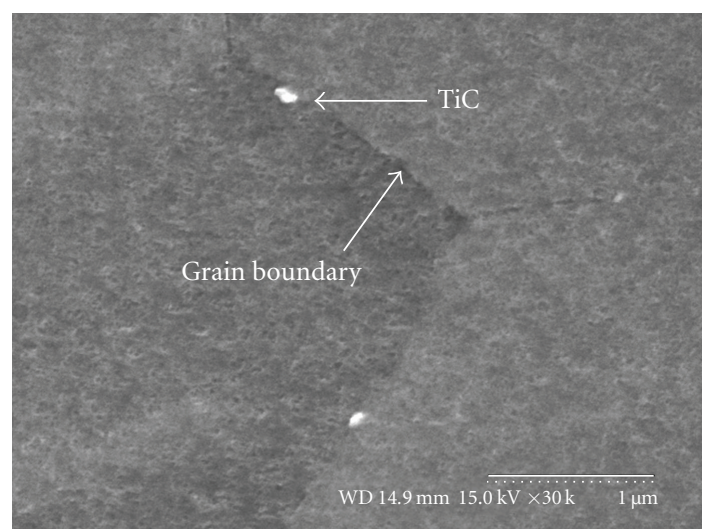

(c)

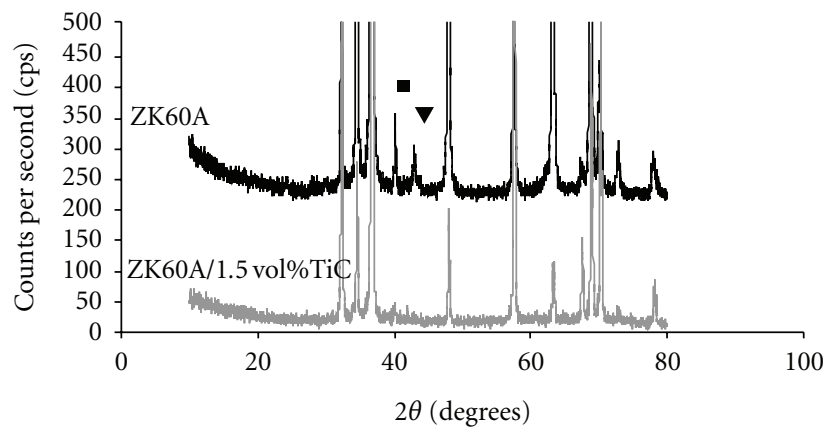

- MgZn

$\boldsymbol{\nabla} \mathrm{Mg}_{2} \mathrm{Zn}_{11}$ (all other peaks correspond to $\mathrm{Mg}$ )

(b)

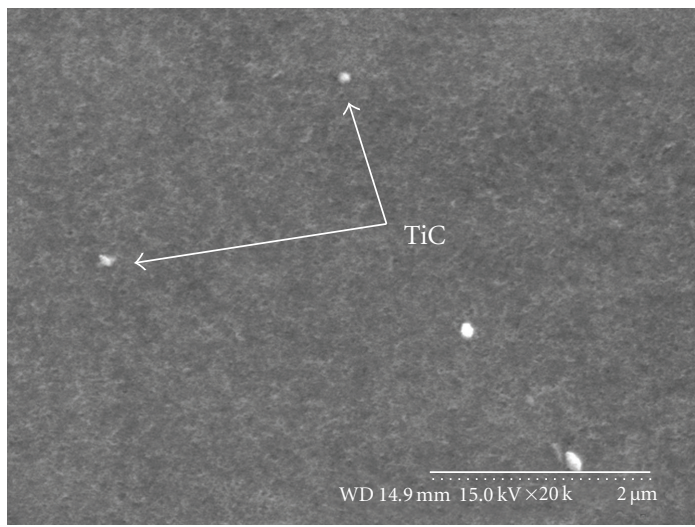

(d)

FIGURE 2: (a) Representative micrograph showing grain size in monolithic ZK60A and ZK60A/TiC nanocomposite. (b) Representative Xray diffraction scans (concerning intermetallic phases) of monolithic ZK60A and ZK60A/TiC nanocomposite. Representative micrographs showing the presence (location) of individual TiC nanoparticles in the ZK60A/TiC nanocomposite (c) at the grain boundary and (d) within the grain.

TABLE 1: Results of grain characteristics and microhardness of ZK60A and ZK60A/TiC nanocomposite.

\begin{tabular}{lcccc}
\hline Material & TiC (vol.\%) & \multicolumn{2}{c}{ Grain characteristics $^{\mathrm{a}}$} & Microhardness $(\mathrm{HV})$ \\
\hline ZK60A & & Size $(\mu \mathrm{m})$ & Aspect ratio & \\
ZK60A/1.5 vol.\% TiC & - & $8.9 \pm 2.0$ & 1.5 & $138 \pm 7$ \\
\hline
\end{tabular}

${ }^{\mathrm{a}}$ Based on approximately 100 grains.

( ) Brackets indicate \% change with respect to corresponding result of ZK60A.

possibly segregated at the liquid-TiC nanoparticle interface enabling intermetallic phase manipulation at the nanoscale. This is similar to possible dissolved $\mathrm{Zn}$ segregation at the liquid-SiC nanoparticle interface enabling nanoscale $\mathrm{MgZn}_{2}$ precipitation as recently reported [12]. With a reasonably uniform 1.5 vol.\% TiC distribution throughout the ZK60A matrix, the nanoparticle-matrix interface area was ample for effectively regulated segregation of $4.80-6.20 \mathrm{wt} . \% \mathrm{Zn}$ (or $1.21-1.59$ vol.\% $\mathrm{Zn}$ ) as nanoscale $\mathrm{Mg}-\mathrm{Zn}$ precipitates. This was similar to that reported recently for ZK60A/1.0 vol.\% CNT nanocomposite [11].
The reasonably uniform distribution of $\mathrm{TiC}$ nanoparticles can be attributed to (a) minimal gravity-associated segregation due to judicious selection of stirring parameters [8], (b) good wetting of $\mathrm{TiC}$ nanoparticles by the alloy matrix [18-20], (c) argon gas disintegration of metallic stream [21], and (d) dynamic deposition of composite slurry on substrate followed by hot extrusion. Similar reasonably uniform distribution of CNT nanoparticles in magnesium alloy ZK60A has also been recently reported [11]. In the nanocomposite, no reaction products based on: (a) $\mathrm{Mg}$ (or $\mathrm{Al}$ ) and $\mathrm{TiC}$ (such as $\mathrm{Mg}_{2} \mathrm{C}_{3}, \mathrm{Al}_{4} \mathrm{C}_{3}$, or Al-Ti-based 
TABLE 2: Texture results of ZK60A and ZK60A/TiC nanocomposite based on X-ray diffraction.

\begin{tabular}{|c|c|c|c|}
\hline Material & Section $^{\mathrm{a}}$ & Plane & Average $\mathrm{I} / \mathrm{I}_{\max }^{\mathrm{b}}$ \\
\hline \multirow{6}{*}{ ZK60A } & \multirow{3}{*}{$\mathrm{T}$} & $10-10$ prism & 0.11 \\
\hline & & 0002 basal & 0.23 \\
\hline & & $10-11$ pyramidal & 1.00 \\
\hline & \multirow{3}{*}{$\mathrm{L}$} & $10-10$ prism & 0.33 \\
\hline & & 0002 basal & 0.58 \\
\hline & & $10-11$ pyramidal & 1.00 \\
\hline \multirow{6}{*}{ ZK60A/1.5 vol.\% TiC } & \multirow{3}{*}{$\mathrm{T}$} & $10-10$ prism & 0.37 \\
\hline & & 0002 basal & 0.06 \\
\hline & & $10-11$ pyramidal & 1.00 \\
\hline & \multirow{3}{*}{$\mathrm{L}$} & $10-10$ prism & 0.32 \\
\hline & & 0002 basal & 0.58 \\
\hline & & $10-11$ pyramidal & 1.00 \\
\hline
\end{tabular}

${ }^{\mathrm{a}} \mathrm{T}$ : transverse, L: longitudinal.

${ }^{b} I_{\max }$ is XRD maximum intensity from either prism, basal, or pyramidal planes.

TABLE 3: Results of tensile testing of ZK60A and ZK60A/TiC nanocomposite.

\begin{tabular}{|c|c|c|c|c|}
\hline Material & $0.2 \%$ TYS (MPa) & UTS (MPa) & Failure strain (\%) & $\mathrm{WOF}\left(\mathrm{MJ} / \mathrm{m}^{3}\right)^{\mathrm{a}}$ \\
\hline ZK60A & $163 \pm 3$ & $268 \pm 3$ & $6.6 \pm 0.6$ & $16 \pm 2$ \\
\hline ZK60A/1.5 vol.\% TiC & $184 \pm 2(+13)$ & $309 \pm 3(+15)$ & $11.6 \pm 1.4(+76)$ & $33 \pm 5(+106)$ \\
\hline
\end{tabular}

${ }^{a}$ Obtained from engineering stress-strain diagram using EXCEL software.

( ) Brackets indicate \% change with respect to corresponding result of ZK60A.

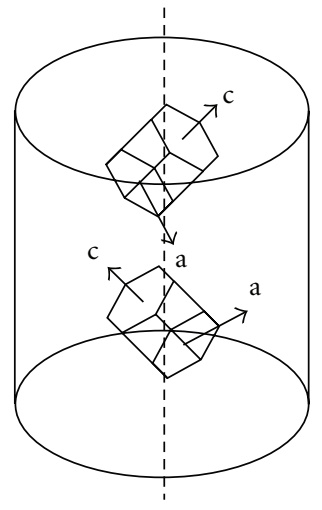

FIGURE 3: Schematic diagram showing textures of monolithic ZK60A and ZK60A/TiC nanocomposite based on X-ray diffraction. In each case, vertical axis (dashed line) is parallel to extrusion direction. Each cell is made up of 2 HCP units having 1 common $\left(\begin{array}{llll}0 & 0 & 0 & 2\end{array}\right)$ basal plane.

intermetallic in this case) and (b) $\mathrm{Al}$ and $\mathrm{Zr}$ (such as fine Al$\mathrm{Zr}$-based intermetallic in this case) having more than $2 \%$ by volume were detected using X-ray diffraction analysis.

\subsection{Mechanical Behavior}

4.3.1. Hardness. A significant decrease in microhardness $(-16 \%)$ was observed in the nanocomposite compared to monolithic material as listed in Table 1. There was lower constraint to localized matrix deformation in the nanocomposite compared to monolithic material. This was despite the reasonably uniform distribution of harder TiC nanoparticles in the nanocomposite (see Figures 2(c) and 2(d)). The decrease in hardness can be primarily attributed to significantly reduced precipitate size of intermetallic phase(s) in the matrix of the nanocomposite compared to monolithic material (see Figure 2(b)).

\subsubsection{Tensile and Compressive Behavior}

Strength. The tensile and compressive strengths of monolithic material and nanocomposite are listed in Tables 3 and 4 (and shown in Figures 4(a) and 4(b)), respectively. 0.2\% TYS and UTS were enhanced ( $+13 \%$ and $+15 \%$, resp.) in ZK60A/1.5 vol.\% TiC compared to monolithic material. The tensile strength increase in ZK60A/1.5 vol.\% TiC compared to monolithic ZK60A was despite the significantly reduced precipitate size of intermetallic phase(s) in the matrix of the nanocomposite compared to monolithic material (see Figure 2(b)). This increase in tensile strength can be attributed to the overall positive effect derived from well-known factors pertaining to reinforcement such as (a) dislocation generation due to elastic modulus mismatch and coefficient of thermal expansion mismatch between the matrix and reinforcement [22-25], (b) Orowan strengthening mechanism [24-26], and (c) load transfer from matrix to reinforcement $[22,24]$.

Regarding compressive strengths, $0.2 \%$ CYS and UCS of $\mathrm{ZK} 60 \mathrm{~A} / 1.5 \mathrm{vol} . \% \mathrm{TiC}$ were lower and higher $(-17 \%$ and $+11 \%$ ), respectively, compared to monolithic ZK60A. The compressive stress detected at any given strain was lower for $\mathrm{ZK} 60 \mathrm{~A} / 1.5 \mathrm{vol} . \% \mathrm{TiC}$ compared to monolithic 


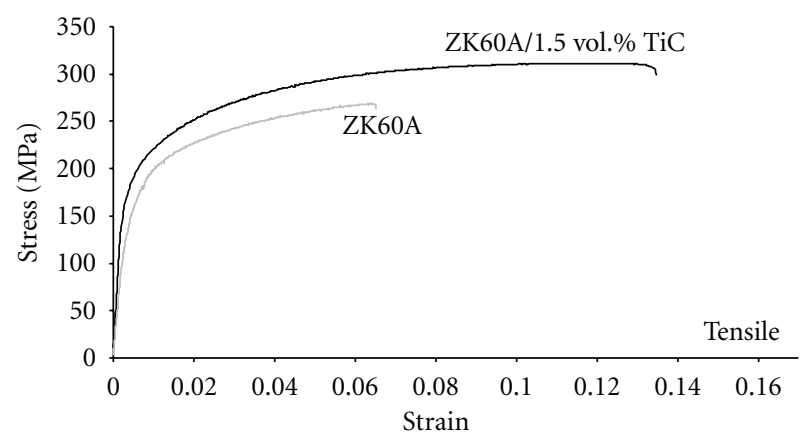

(a)

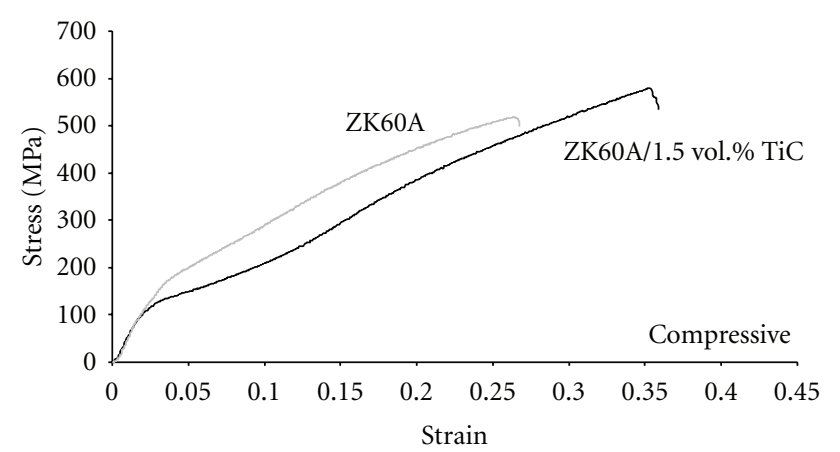

(b)

FIGURE 4: Representative: (a) tensile and (b) compressive stress-strain curves of monolithic ZK60A and ZK60A/TiC nanocomposite.

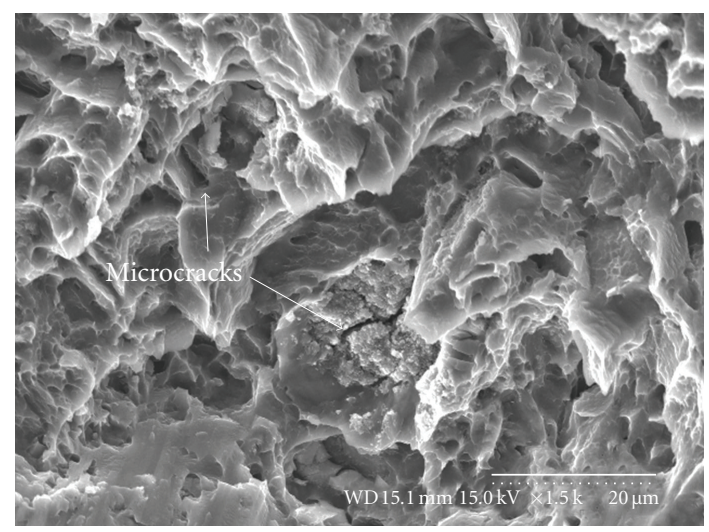

(a)

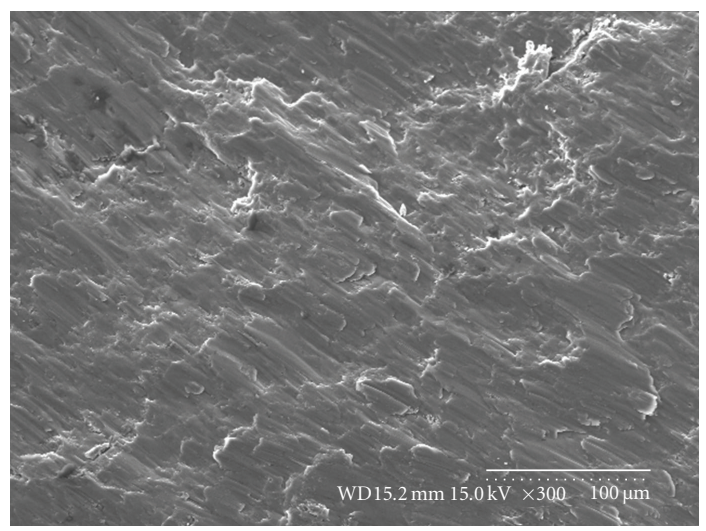

(c)

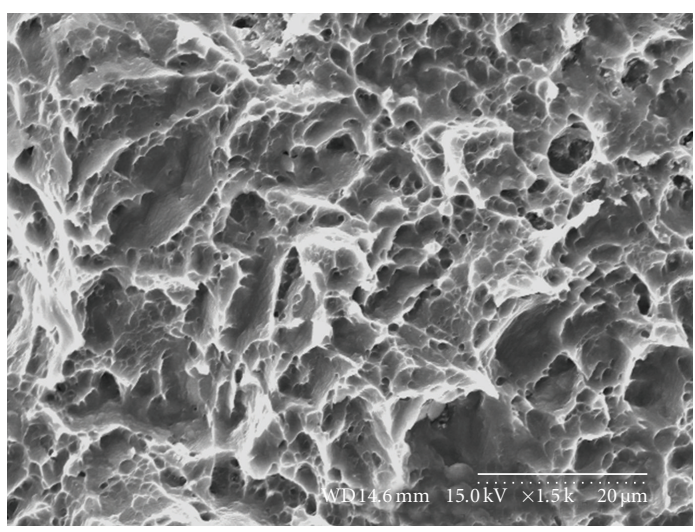

(b)

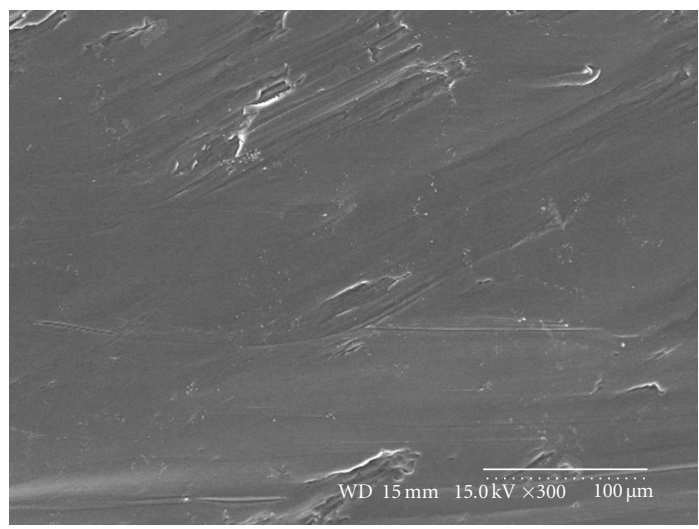

(d)

FIGURE 5: Representative tensile fractographs of (a) monolithic ZK60A and (b) ZK60A/TiC nanocomposite. Representative compressive fractographs of (c) monolithic ZK60A and (d) ZK60A/TiC nanocomposite.

TABLE 4: Results of compressive testing of ZK60A and ZK60A/TiC nanocomposite.

\begin{tabular}{lcccc}
\hline Material & $0.2 \%$ CYS $(\mathrm{MPa})$ & UCS $(\mathrm{MPa})$ & Failure strain $(\%)$ & WOF $\left(\mathrm{MJ} / \mathrm{m}^{3}\right)^{\mathrm{a}}$ \\
\hline ZK60A & $128 \pm 11$ & $522 \pm 11$ & $19.6 \pm 0.9$ & $89 \pm 12$ \\
ZK60A/1.5 vol.\% TiC & $106 \pm 7(-17)$ & $577 \pm 6(+11)$ & $25.3 \pm 1.6(+29)$ & $119 \pm 5(+34)$ \\
\hline
\end{tabular}

${ }^{a}$ Obtained from engineering stress-strain diagram using EXCEL software.

( ) Brackets indicate \% change with respect to corresponding result of ZK60A. 
ZK60A as shown in Figure 4(b). This was despite the factors pertaining to reinforcement (as just described in the paragraph before this). This lower compressive strength in ZK60A/1.5 vol.\% TiC compared to monolithic ZK60A can be attributed to the overall negative effect derived from (a) significantly reduced precipitate size of intermetallic phase(s) in the matrix of the nanocomposite compared to monolithic material and (b) compressive shear buckling of Mg-Zn-based nanoscale rod/disc intermetallic as illustrated in Figure 6. The dominant presence of (a) Mg-Zn-based nanoscale rod intermetallic (lying parallel to the c-axis of the HCP unit cell) and (b) Mg-Zn based nanoscale disc intermetallic (lying parallel to the basal plane of the HCP unit cell) in MgZn systems is well known $[1,27]$. The compressive shear buckling of Mg-Zn-based nanoscale rod/disc intermetallic induced a significantly lower limit on the strengthening factors pertaining to reinforcement (as just described in the paragraph before this). This was dissimilar to that reported recently for ZK60A/1.0 vol.\% CNT nanocomposite, where CNT buckling in the ZK60A matrix was the reason compressive stress detected at any given strain was lower for ZK60A/1.0 vol.\% CNT compared to monolithic ZK60A [11].

In monolithic ZK60A, $0.2 \%$ TYS was about 1.27 times the $0.2 \%$ CYS. Here, near tensile/compressive yield stress isotropy was present despite half the strain rate used (less strain hardening) in compressive testing compared to tensile

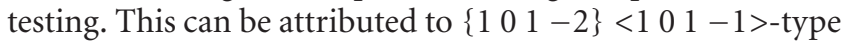
twinning being activated along the c-axis of the HCP unit cell in Figure 3 (see Table 2 also) with comparatively similar ease in both tension and compression along the c-axis, based on the $45^{\circ}$ angle between the c-axis and the vertical axis [20, $28,29]$. In the case of $\mathrm{ZK} 60 \mathrm{~A} / 1.5 \mathrm{vol} . \% \mathrm{TiC}, 0.2 \%$ TYS was about 1.74 times the $0.2 \%$ CYS despite the similarity in crystallographic texture compared to monolithic ZK60A. Here, the significant tensile/compressive yield stress anisotropy can be attributed to compressive shear buckling of $\mathrm{Mg}$ - $\mathrm{Zn}$-based nanoscale rod/disc intermetallic in ZK60A/1.5 vol.\% TiC as illustrated in Figure 6. The Mg-Zn-based nanoscale rod/disc intermetallic is prone to buckling followed by fracture within the ZK60A matrix during compressive deformation unlike during tensile deformation. This was similar to that reported recently for ZK60A/1.0 vol.\% CNT nanocomposite [11].

Failure Strain. The tensile and compressive failure strains of monolithic material and nanocomposite are listed in Tables 3 and 4 (and shown in Figures 4(a) and 4(b)), respectively. Compared to monolithic material, tensile and compressive failure strains were enhanced by $76 \%$ and $29 \%$, respectively in $\mathrm{ZK} 60 \mathrm{~A} / 1.5 \mathrm{vol} \%$ TiC. The failure strain increase in ZK60A/1.5 vol.\% TiC compared to monolithic ZK60A can be attributed to the following factors pertaining to reinforcement: (a) presence and reasonably uniform distribution of TiC nanoparticles [30, 31], (b) reduction in size of intermetallic phase(s) [32], and (c) compressive shear buckling of Mg-Zn-based nanoscale rod/disc intermetallic as illustrated in Figure 6 (regarding compressive failure strain only). In the case of reasonably uniform distribution of TiC nanoparticles, it has been shown in previous studies that nanoparticles provide sites where cleavage cracks are opened ahead of the advancing crack front. This (1) dissipates the stress concentration which would otherwise exist at the crack front and (2) alters the local effective stress state from plane strain to plane stress in the neighbourhood of the crack tip $[30,31]$. In the case of reduction in size of intermetallic phase(s), redistribution of smaller intermetallic phase(s) (compare between predominantly aggregated type and dispersed type) can assist in improving ductility [32]. Regarding compressive shear buckling of $\mathrm{Mg}$-Zn-based nanoscale rod/disc intermetallic, such nanoscale buckling within the ZK60A matrix aids in dispersing localized stored energy during compressive deformation. This allows ZK60A/1.5 vol.\% TiC to globally absorb relatively large amounts of strain energy during compressive deformation [11,33]. Here, Mg-Znbased nanoscale rod/disc intermetallic buckling within the ZK60A matrix is a compressive toughening mechanism. This was dissimilar to that reported recently for ZK60A/1.0 vol.\% CNT nanocomposite, where CNT buckling in the ZK60A matrix was one of the reasons compressive failure strain was higher for ZK60A/1.0 vol.\% CNT compared to monolithic ZK60A [11].

Tensile fracture behaviour of both monolithic material and nanocomposite was mixed (ductile + brittle) as shown in Figures 5(a) and 5(b). However, the tensile fractured surface of the nanocomposite had (a) higher occurrence of smaller dimple-like features and (b) absence of microcracks compared to that of monolithic material. The tensile cavitation resistance was lower and the microcrack formation resistance was higher in the nanocomposite compared to monolithic material. For ZK60A/1.5 vol.\% TiC, compressive fracture behavior based on viscoplastic flow [34] was relatively more ductile (smoother fracture surface exhibited) compared to monolithic ZK60A as shown in Figures 5(c) and 5(d). This relatively more ductile compressive fracture behavior can be attributed to increase in shear band spacing $[34,35]$.

Work of Fracture. The tensile and compressive work of fracture (WOF) of monolithic material and nanocomposite are listed in Tables 3 and 4 (and illustrated in Figures 4(a) and $4(\mathrm{~b})$ ), respectively. WOF quantified the ability of the material to absorb energy up to fracture under load [36]. Compared to monolithic material, tensile and compressive WOF were enhanced by $106 \%$ and 34\% (resp.) in ZK60A/1.5 vol.\% TiC. The significantly high increments in tensile and compressive WOF exhibited by ZK60A/1.5 vol.\% TiC show its potential to be used in damage tolerant design.

\section{Conclusions}

(1) Monolithic ZK60A and ZK60A/1.5 vol.\% TiC nanocomposite can be successfully synthesized using the DMD technique followed by hot extrusion.

(2) Compared to monolithic ZK60A, tensile strength of $\mathrm{ZK} 60 \mathrm{~A} / 1.5 \mathrm{vol} \% \mathrm{TiC}$ was enhanced. This can be attributed to the overall positive effect derived 


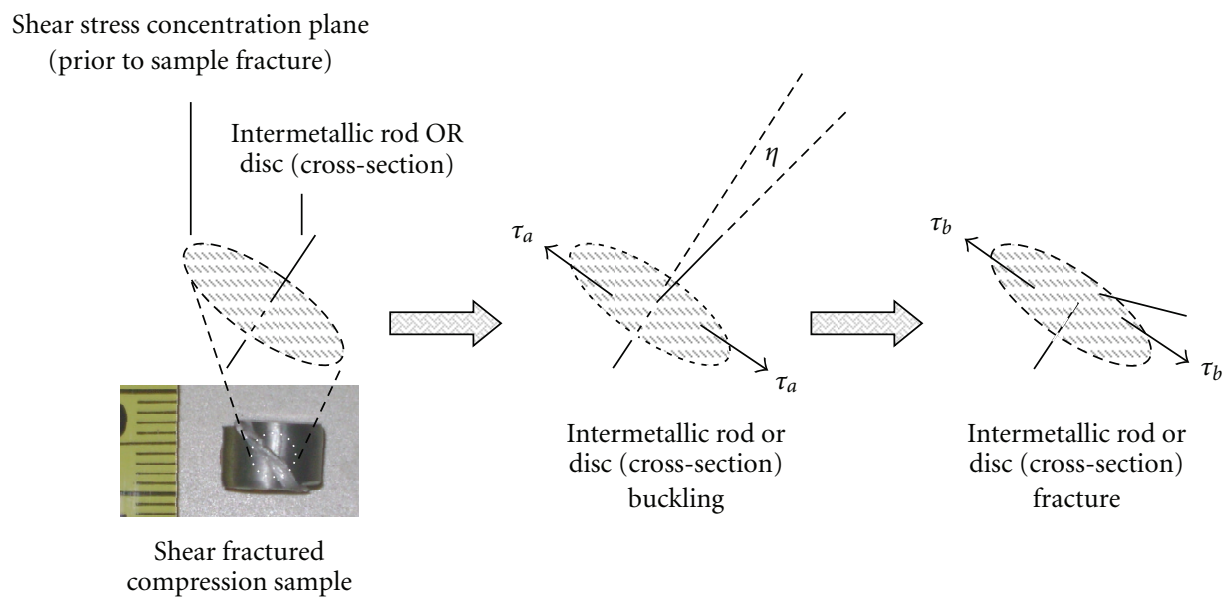

FIGURE 6: Schematic diagram illustrating compressive shear buckling of nanoscale rod/disc intermetallic in ZK60A/TiC nanocomposite. $\tau_{a}$ and $\tau_{b}$ represent planar shear stresses, where $\tau_{a}<\tau_{b} . \eta$ (exaggerated) represents very low angular deflection of the brittle rod/disc intermetallic during buckling.

from well-known factors pertaining to reinforcement. Compared to monolithic ZK60A, compressive strength of $\mathrm{ZK} 60 \mathrm{~A} / 1.5 \mathrm{vol} . \% \mathrm{TiC}$ was generally decreased. The $0.2 \%$ CYS and UCS of ZK60A/1.5 vol.\% TiC were lower and higher than that of monolithic ZK60A, respectively. This can be attributed to the overall negative effect derived from (a) significantly reduced precipitate size of intermetallic phase(s) in the matrix of the nanocomposite compared to monolithic material and (b) compressive shear buckling of $\mathrm{Mg}-\mathrm{Zn}$-based nanoscale $\mathrm{rod} /$ disc intermetallic in the nanocomposite.

(3) Compared to monolithic ZK60A, tensile and compressive failure strains of $\mathrm{ZK} 60 \mathrm{~A} / 1.5 \mathrm{vol} \% \% \mathrm{TiC}$ were significantly enhanced. This can be attributed to the following factors pertaining to reinforcement: (a) presence and reasonably uniform distribution of $\mathrm{TiC}$ nanoparticles, (b) reduction in size of intermetallic phase(s), and (c) compressive shear buckling of Mg$\mathrm{Zn}$-based nanoscale rod/disc intermetallic (regarding compressive failure strain only).

(4) Compared to monolithic ZK60A, ZK60A/1.5 vol.\% TiC exhibited significantly high increments in tensile and compressive WOF.

\section{Acknowledgments}

Authors wish to acknowledge National University of Singapore (NUS) and Temasek Defence Systems Institute (TDSI) for funding this research (TDSI/09-011/1A and WBS no. R265000349).

\section{References}

[1] M. M. Avedesian and H. Baker, ASM Specialty Handbook: Magnesium and Magnesium Alloys, ASM International, Materials Park, Ohio, USA, 1999.
[2] X. Gao and J. F. Nie, "Characterization of strengthening precipitate phases in a Mg-Zn alloy," Scripta Materialia, vol. 56, no. 8, pp. 645-648, 2007.

[3] J. B. Clark, "Transmission electron microscopy study of age hardening in a Mg-5 wt.\% Zn alloy," Acta Metallurgica, vol. 13, no. 12, pp. 1281-1289, 1965.

[4] L. L. Rokhlin and A. A. Oreshkina, "Structural investigation of the metastable phase that forms during decomposition of the supersaturated solid solution in magnesium-zinc alloys," Physics of Metals and Metallography, vol. 66, no. 3, pp. 130134, 1988.

[5] J. S. Chun and J. G. Byrne, "Precipitate strengthening mechanisms in magnesium zinc alloy single crystals," Journal of Materials Science, vol. 4, no. 10, pp. 861-872, 1969.

[6] L. Y. Wei, G. L. Dunlop, and H. Westengen, "Precipitation hardening of Mg-Zn and Mg-Zn-RE alloys," Metallurgical and Materials Transactions A, vol. 26, no. 7, pp. 1705-1716, 1995.

[7] D. H. Bae, M. H. Lee, K. T. Kim, W. T. Kim, and D. H. Kim, "Application of quasicrystalline particles as a strengthening phase in Mg-Zn-Y alloys," Journal of Alloys and Compounds, vol. 342, no. 1-2, pp. 445-450, 2002.

[8] L. K. Tham, M. Gupta, and L. Cheng, "Influence of processing parameters during disintegrated melt deposition processing on near net shape synthesis of aluminium based metal matrix composites," Materials Science and Technology, vol. 15, no. 10, pp. 1139-1146, 1999.

[9] M. Gupta, M. O. Lai, and S. C. Lim, "Regarding the processing associated microstructure and mechanical properties improvement of an Al-4.5 Cu alloy," Journal of Alloys and Compounds, vol. 260, no. 1-2, pp. 250-255, 1997.

[10] P. Jayaramanavar, M. Paramsothy, A. Balaji, and M. Gupta, "Tailoring the tensile/compressive response of magnesium alloy ZK60A using $\mathrm{Al}_{2} \mathrm{O}_{3}$ nanoparticles," Journal of Materials Science, vol. 45, no. 5, pp. 1170-1178, 2010.

[11] M. Paramsothy, J. Chan, R. Kwok, and M. Gupta, "Addition of CNTs to enhance tensile/compressive response of magnesium alloy ZK60A," Composites Part A, vol. 42, no. 2, pp. 180-188, 2011. 
[12] M. De Cicco, H. Konishi, G. Cao et al., "Strong, ductile magnesium-zinc nanocomposites," Metallurgical and Materials Transactions A, vol. 40, no. 12, pp. 3038-3045, 2009.

[13] A. Contreras, C. Angeles-Chavez, O. Flores, and R. Perez, "Structural, morphological and interfacial characterization of Al-Mg/TiC composites," Materials Characterization, vol. 58, no. 8-9, pp. 685-693, 2007.

[14] J. J. Wang, J. H. Guo, and L. Q. Chen, “TiC/AZ91D composites fabricated by in situ reactive infiltration process and its tensile deformation," Transactions of Nonferrous Metals Society of China, vol. 16, no. 4, pp. 892-896, 2006.

[15] Y. Chen, Y. C. Wu, F. W. Yu, and J. L. Chen, "Microstructure and mechanical properties of tungsten composites costrengthened by dispersed $\mathrm{TiC}$ and $\mathrm{La}_{2} \mathrm{O}_{3}$ particles," International Journal of Refractory Metals and Hard Materials, vol. 26, no. 6, pp. 525-529, 2008.

[16] K. Kondoh, T. Threrujirapapong, H. Imai, J. Umeda, and B. Fugetsu, "CNTs/TiC reinforced titanium matrix nanocomposites via powder metallurgy and its microstructural and mechanical properties," Journal of Nanomaterials, vol. 2008, no. 1, Article ID 127538, p. 4, 2008.

[17] B. D. Cullity, Elements of X-Ray Diffraction, Addison-Wesley, Reading, Mass, USA, 2nd edition, 1978.

[18] N. Eustathopoulos, M. G. Nicholas, and B. Drevet, Wettability at High Temperatures, Volume 3, Pergamon Materials, Pergamon, New York, NY, USA, 1999.

[19] J. D. Gilchrist, Extraction Metallurgy, Pergamon Press, New York, NY, USA, 3rd edition, 1989.

[20] M. Paramsothy, S. F. Hassan, N. Srikanth, and M. Gupta, "Adding carbon nanotubes and integrating with AA5052 aluminium alloy core to simultaneously enhance stiffness, strength and failure strain of AZ31 magnesium alloy," Composites Part A, vol. 40, no. 9, pp. 1490-1500, 2009.

[21] M. Gupta, M. O. Lai, and C. Y. Soo, "Effect of type of processing on the micro structural features and mechanical properties of $\mathrm{Al}-\mathrm{Cu} / \mathrm{SiC}$ metal matrix composites," Materials Science and Engineering A, vol. 210, no. 1-2, pp. 114-122, 1996.

[22] S. F. Hassan and M. Gupta, "Effect of different types of nanosize oxide participates on microstructural and mechanical properties of elemental Mg," Journal of Materials Science, vol. 41, no. 8, pp. 2229-2236, 2006.

[23] C. S. Goh, J. Wei, L. C. Lee, and M. Gupta, "Development of novel carbon nanotube reinforced magnesium nanocomposites using the powder metallurgy technique," Nanotechnology, vol. 17, no. 1, pp. 7-12, 2006.

[24] Z. Szaraz, Z. Trojanova, M. Cabbibo, and E. Evangelista, "Strengthening in a WE54 magnesium alloy containing $\mathrm{SiC}$ particles," Materials Science and Engineering A, vol. 462, no. 1-2, pp. 225-229, 2007.

[25] L. H. Dai, Z. Ling, and Y. L. Bai, "Size-dependent inelastic behavior of particle-reinforced metal-matrix composites," Composites Science and Technology, vol. 61, no. 8, pp. 10571063, 2001.

[26] D. Hull and D. J. Bacon, Introduction to Dislocations, Butterworth Heinemann, Oxford, UK, 4th edition, 2002.

[27] W. J. Kim, M. J. Kim, and J. Y. Wang, "Superplastic behavior of a fine-grained ZK60 magnesium alloy processed by high-ratio differential speed rolling," Materials Science and Engineering A, vol. 527, no. 1-2, pp. 322-327, 2009.

[28] T. Laser, C. Hartig, M. R. Nurnberg, D. Letzig, and R. Bormann, "The influence of calcium and cerium mischmetal on the microstructural evolution of $\mathrm{Mg}-3 \mathrm{Al}-1 \mathrm{Zn}$ during extrusion and resulting mechanical properties," Acta Materialia, vol. 56, no. 12, pp. 2791-2798, 2008.

[29] J. Bohlen, S. B. Yi, J. Swiostek, D. Letzig, H. G. Brokmeier, and K. U. Kainer, "Microstructure and texture development during hydrostatic extrusion of magnesium alloy AZ31," Scripta Materialia, vol. 53, no. 2, pp. 259-264, 2005.

[30] S. F. Hassan and M. Gupta, "Development of nano- $\mathrm{Y}_{2} \mathrm{O}_{3}$ containing magnesium nanocomposites using solidification processing," Journal of Alloys and Compounds, vol. 429, no. 12, pp. 176-183, 2007.

[31] S. F. Hassan and M. Gupta, "Effect of particulate size of $\mathrm{Al}_{2} \mathrm{O}_{3}$ reinforcement on microstructure and mechanical behavior of solidification processed elemental Mg," Journal of Alloys and Compounds, vol. 419, no. 1-2, pp. 84-90, 2006.

[32] G. E. Dieter, Mechanical Metallurgy, SI Metric, McGraw-Hill, London, UK, 1998.

[33] S. Namilae and N. Chandra, "Role of atomic scale interfaces in the compressive behavior of carbon nanotubes in composites," Composites Science and Technology, vol. 66, no. 13, pp. 20302038, 2006.

[34] R. C. Batra and Z. G. Wei, "Instability strain and shear band spacing in simple tensile/compressive deformations of thermoviscoplastic materials," International Journal of Impact Engineering, vol. 34, no. 3, pp. 448-463, 2007.

[35] T. S. Wang, R. J. Hou, B. Lv, M. Zhang, and F. C. Zhang, "Microstructure evolution and deformation mechanism change in $0.98 \mathrm{C}-8.3 \mathrm{Mn}-0.04 \mathrm{~N}$ steel during compressive deformation," Materials Science and Engineering A, vol. 465, no. 1-2, pp. 68-71, 2007.

[36] R. E. Reed-Hill, Physical Metallurgy Principles, D Van Nostrand, New York, NY, USA, 2nd edition, 1964. 

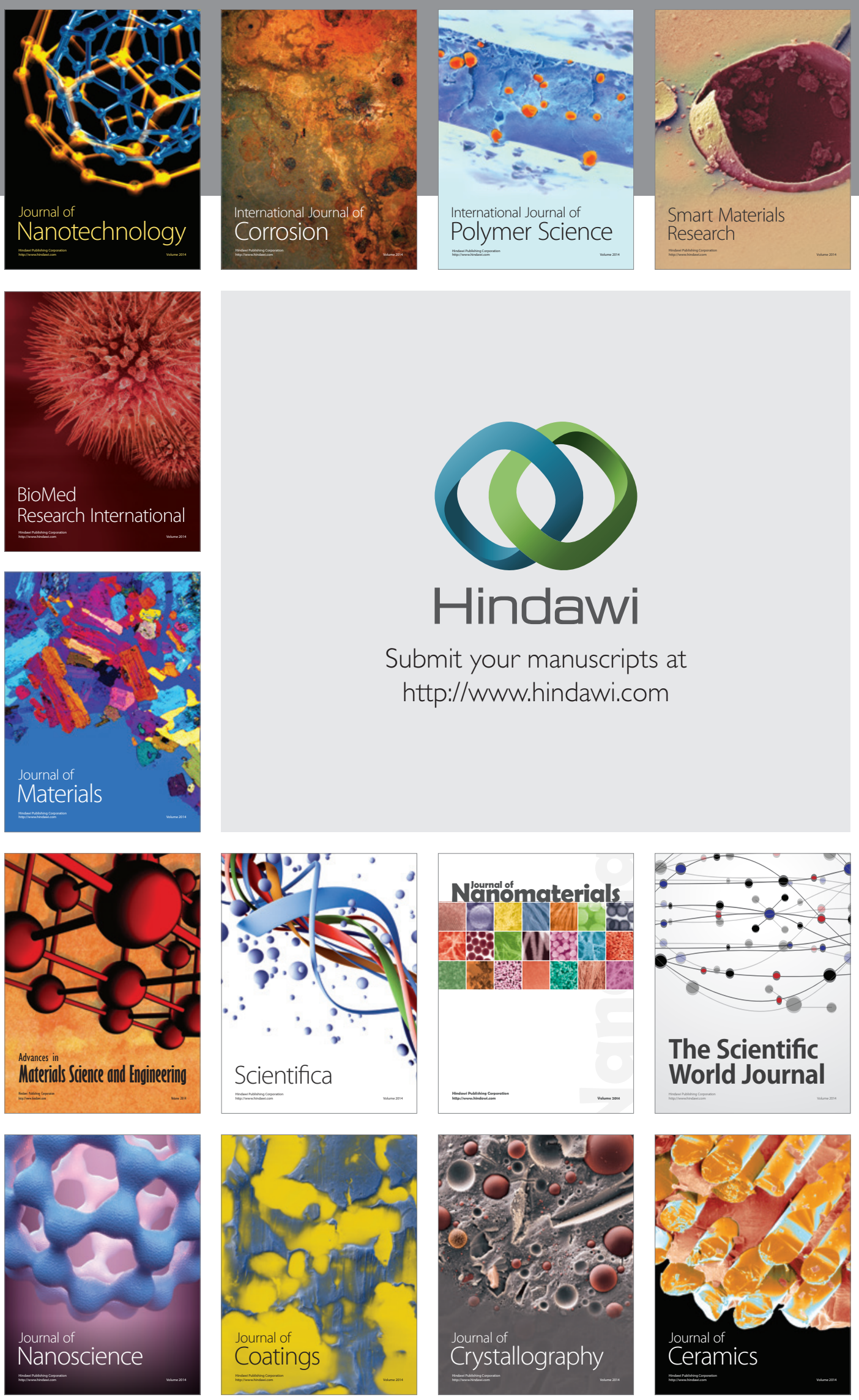

The Scientific World Journal

Submit your manuscripts at

http://www.hindawi.com

\section{World Journal}

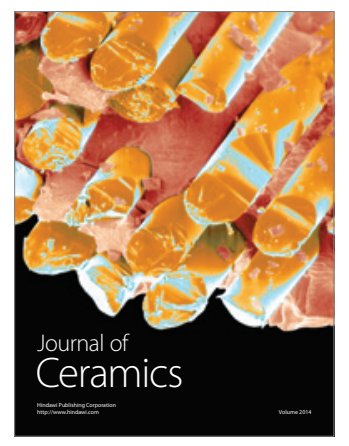

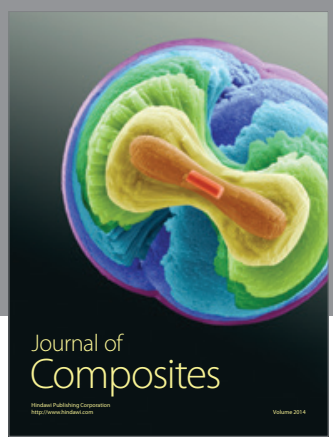
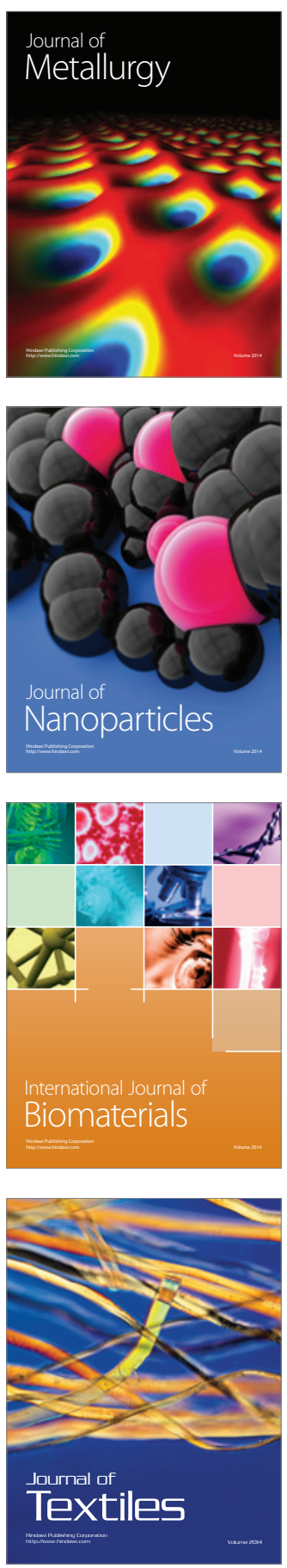